\title{
Spatially discrete linear optimization of manure transports with a focus on supply for biomass power plants in agriculture
}

\author{
$\underline{\text { M. Biberacher }}^{\text {a }}$ and S. Warnecke ${ }^{\text {b }}$ \\ ${ }^{a}$ Research Studios Austria Forschungsgesellschaft mbH \\ Schillerstrasse 25, A-5020, Salzburg, Austria \\ ${ }^{b}$ Thünen Institute of Organic Farming \\ Trenthorst 32, D-23847, Westerau, Germany
}

Email: markus.biberacher@researchstudio.at

\begin{abstract}
High-intensity livestock farming on a regional level often faces the problem of surplus animal manure with respect to legal application limits to cropland. Manure is both a valuable fertilizer and a valuable fuel for biomass power plants. However, it triggers logistic challenges if the local manure nutrient amount is beyond the local fertilization demand of crops, and/or beyond the legal threshold for the application of animal manure nutrients and/or beyond the biomass demand of local biomass power plants.
\end{abstract}

We present a linear optimization approach which identifies optimal manure transports (at lowest transport effort given as the product of distance and mass, $\mathrm{km} *$ tonnes) between individual spatial units within a defined region. The optimization takes place within the constraints of (a) meeting both crop nutrient demands and manure application limits, (b) providing energy crops and manure for local capacities of biomass power plants, and (c) costs for transportation. Costs for artificial fertilizers can, but do not have to, be integrated to show how much of the manure transports are economically feasible in competition to artificial fertilizers. For this study, the model optimizes manure use and transport in a region with 1047 spatial units and a total of 2.6 Mega hectares of agricultural land in northwest Germany. Each spatial unit comprises 25 livestock categories with up to three manure categories each, 13 crop categories (two of which can be used as energy crops), and a capacity of producing energy in biomass power plants. As an example on what might be analyzed with the model we present the results of a scenario analysis on a specific feeding strategy for biomass power plants (60\% renewable raw materials and 40\% manure as supported by the 2012 version of the German Renewable Energy Act). Both the costs for mineral fertilizers and for transportation of manure were included into this analysis. For example, the results show (a) what kind of manure and how much of it needs to be transported how far, (b) where the manure predominantly originates from and where it goes to, (c) how much and what kind of manure and how much energy crop is used for energy production, (d) how much of the transports are economically feasible. In the scenario's results, liquid manure largely remained in the spatial unit where it originated from while solid manure was transported over larger distances. $76 \%$ of the biogas produced in the region was generated from maize silage and $24 \%$ was generated from manure, with solid manure serving as main manure input. Only $25 \%$ of the nitrogen demand of the crops in the region was covered by manure. For the remaining $75 \%$ it proved cheaper to use artificial fertilizers at the given price than transporting manure over larger distances.

The model framework allows for a sensitivity analysis across varying assumptions and constraints regarding the complex regional nutrient balance between intensive livestock farming and arable farming with special focus on energy production from biomass (both manure and maize). To enable realistic analyses in the future according to future legal aspects, the model shall be expanded to include nutrient use and transports of biogas digestates.

Keywords: Linear optimization, spatial modelling, agricultural nutrient balance, supply/demand, bioenergy 
Biberacher and Warnecke, Spatially discrete linear optimization of manure transports...

\section{INTRODUCTION}

Regionally concentrated high intensive animal farming results in large amounts of manure with nutrient amounts far beyond the demand of the agricultural crops. Besides using manure as a fertilizer it could also be used as a resource for producing energy via bio-methane. This combined way of utilization of manure in high intensive animal farming and agricultural areas is accompanied by some logistic problems in finding the optimal transport flows for manure in order to satisfy all needs best. We present a model which calculates optimal transport flows for manure based on manure supply by animal farming, nutrient demand for agriculture and resource demand of biogas plants, and the related transport distances in between. This model is an update to the model presented by Biberacher et al. (2009) which treated only the nutrient balance and related manure transport flows and which was applied to the NUTS 2 level as opposed to the LAU 2 level.

The study area is Lower Saxony in north-west Germany and consists of a total of 1047 administrative spatial units on the LAU 2 level. We refer to them as the municipality level. Of the total land area of $47,635 \mathrm{~km}^{2}$, $60 \%$ were agricultural land. Regional specialization of agricultural production had occurred in the past decades. As a result, intense animal husbandry including upstream and downstream industries prevails in the Weser-Ems region in the region's west while arable farming dominates the agricultural production in its east and south-east. In addition to the large amounts of manure in the west of the study area there are several clusters of high biogas power capacity. Biogas power plants can be operated with a more or less varying proportion of different renewable raw materials (e.g. maize or whole-plant silage) and different manures.

The model we present here deals with these issues and suggests an optimal setup of transport flows for manure and energy crops among the different spatial units with regard to assumptions made for a specific scenario. In the model, the biogas plant capacity installed in a spatial unit can be filled with a defined share of energy crops while the remaining share has to be covered by manure (all manure classes may be used). In this study, our focus lies on showing how the model operates.

\section{MODEL}

For this study we detailed the linear optimization model described by Biberacher et al. (2009) from the NUTS 3 to the LAU 2 level. The model solves a distribution problem: Various animal farm manures are to be distributed to different agricultural land use classes or biogas plants in individual spatial units of a model region. The objective of the model is to identify the least costly manure transport solution for identified scenario assumptions under the consideration of specific manure transport costs, the revenues from produced electricity in biogas power plants and the price for mineral fertilizers in competition to manure.

The model is implemented in GAMS (General Algebraic Modelling System, GAMS 2015). The model is linked to an Excel template for data input. The constraints for manure nutrient distribution are defined individually for single scenarios. The model output is a) manure nutrient deficient or surplus spatial units for each of the nutrients Nitrogen (N), Phosphorous (P), Potassium (K) and b) the optimal manure distribution to the agricultural land and biogas plants by considering minimal manure transports between all spatial units at lowest overall transport effort (expressed as tonnes by kilometers). We use MS-Excel to process the results.

\subsection{Data}

In general, we use parameters, coefficients, and rates such as nutrient excretion of animals released by the relevant authorities on the Lower Saxonian level. All data sets we use are valid for the year 2010. We determined the number of farm animals on the municipality level by combining the official agro-statistical figures on farm animals from May 2007 (available on municipality level) with data from the compulsory animal insurance scheme in Lower Saxony (TSK 2009) from December 2009 (available on district level only). The livestock categories cattle, pig, poultry, horse, and sheep consist of a total of 25 animal classes (5, $5,6,4$, and 1 classes each). In the model, we make distinctions for the different kinds of manure generated in different housing systems ( 1 solid manure class, 2 classes of liquid manure) or the excrements directly dropped on pastures (1 class), respectively. The basis for the land use data used in the model is data of the EU's Integrated Administration and Control System (IACS) and aggregated them to 11 classes of arable crops and 2 classes of permanent grassland. We determined the fertilizer demand for each of the 12 soilclimate-zones detailed for Lower Saxony.

According to the German Fertilizer Ordinance (2007) farmers may apply no more than $170 \mathrm{~kg}$ of $\mathrm{N}$ per hectare (farm average) from animal excretions. For the modelling, we assumed the same. Also, farmers may not exceed the annual P balance beyond $20 \mathrm{~kg} \mathrm{P}_{2} \mathrm{O}_{5}$ per hectare (as a six years average). For the modelling, 
Biberacher and Warnecke, Spatially discrete linear optimization of manure transports...

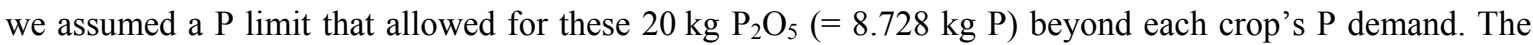
Fertilizer Ordinance gives no limits in fertilizing $\mathrm{K}$ so we put no constraint for $\mathrm{K}$ (except for potatoes: They received $\mathrm{K}$ according to their $\mathrm{K}$ demand since they react with quality decrease at the presence of excess $\mathrm{K}$ ).

To identify manure transport streams for a cost optimal scenario, we assumed transport costs for manure as $0.10 € \mathrm{t}^{-1} \mathrm{~km}^{-1}$ and the costs for artificial fertilizer as $1 € \mathrm{~kg}^{-1}$ for $\mathrm{N}, 1.3 € \mathrm{~kg}^{-1}$ for $\mathrm{P}$ and $0.8 € \mathrm{~kg}^{-1} \mathrm{for} \mathrm{K}_{\mathrm{K}}$ (which was the average cost level of 2009 in Lower Saxony).

The number of biogas plants in June 2010 using renewable raw materials and the electrical power installed per plant (Ministry of Agriculture of Lower Saxony 2010, unpublished) was aggregated to the municipality level. At that time, a total of $550 \mathrm{MW}$ electrical power were installed in Lower Saxony. For the modelling we assumed that the biogas plants were operated with 8,000 full load hours per year (see equations). Power yields were assumed according to KTBL (2009) for each manure class. For the scenario, the feeding strategy for all biomass power plants was $60 \%$ energy crops and $40 \%$ manure.

\subsection{Model setup}

The model aims at optimizing animal farm manure distribution in and transport between spatial units (municipalities) in a model region (federal state). It considers constraints for the application of manures to agricultural acreage as well as transportation costs. The model assumptions are listed in Table 2 while Table 1 details notations of indices, variables and parameters used.

Table 1. Notations for indices, variables and parameters as used in the relations and equations of the model.

\begin{tabular}{|c|c|}
\hline \multicolumn{2}{|l|}{ Indices } \\
\hline$s$ & spatial unit \\
\hline$r$ & spatial unit different from spatial unit $(s)$ which neighbours spatial unit $(s)$ \\
\hline$n$ & nutrient class \\
\hline$c$ & crop class \\
\hline$f$ & pasture class (subset of crop class $(c)$ ) \\
\hline$g$ & manure class \\
\hline$h$ & animal class \\
\hline$p(h)$ & poultry class \\
\hline \multicolumn{2}{|c|}{ Variables } \\
\hline$d_{s, c, h, g}$ & application of manure class $(g)$ of animal class $(h)$ on crop class $(c)$ in spatial unit $(s)$ \\
\hline$t_{s, r, h, g}$ & transport of manure class $(g)$ of animal class $(h)$ from spatial unit $(s)$ to a neighboring spatial unit $(r)$ \\
\hline$e x_{s, h, g}$ & $\begin{array}{l}\text { global export of manure class }(g) \text { of animal class }(h) \text { from spatial unit }(s) \text { beyond the model region } \\
\text { (slack variable) }\end{array}$ \\
\hline$t n_{s, r}$ & transport of maize for biogas from spatial unit $(s)$ to a neighboring spatial unit $(r)$ \\
\hline$t \_g_{s, r}$ & transport of GPS (whole-plant silage)for biogas from spatial unit $(s)$ to a neighboring spatial unit $(r)$ \\
\hline $\overrightarrow{b g_{s, h, g}}$ & input in biogas plant of manure class $(g)$ of animal class $(h)$ from spatial unit $(s)$ \\
\hline$o \_n_{s}$ & maize for biogas plants produced in spatial unit $(s)$ \\
\hline$f n_{s}$ & maize input in biogas plant in spatial unit $(s)$ \\
\hline$o \_g_{s}$ & GPS for biogas plants produced in spatial unit $(s)$ \\
\hline$f g_{s}$ & GPS input in biogas plant in spatial unit $(s)$ \\
\hline \multicolumn{2}{|c|}{ Parameters } \\
\hline$l_{n, c}$ & specific nutrient $(n)$ constraint for crop class $(c)$ \\
\hline$a_{s, c}$ & total area of crop class $(c)$ in spatial unit $(s)$ \\
\hline$b_{h, g, n}$ & specific nutrient $(n)$ content of manure class $(g)$ of animal class $(h)$ \\
\hline$u_{s, h, g}$ & number of animals in animal class $(h)$ with manure class $(g)$ in spatial unit $(s)$ \\
\hline$m_{h, g}$ & annual amount of manure in manure class $(g)$ of one animal of animal class $(h)$ \\
\hline$w_{s, r}$ & distance between neighbouring spatial units $(s)$ and $(r)$ \\
\hline$k$ & specific transport costs (costs per distance unit and mass unit) \\
\hline$p$ & global specific transport costs (costs per mass unit) for transports beyond model region \\
\hline$z_{n}$ & specific cost for fertilizer of nutrient $(n)$ \\
\hline$B_{s}$ & biogas plant capacity in region $(s)$ \\
\hline$N g_{s}$ & maize growth in tonnes/ha in region $(s)$ \\
\hline$G g_{s}$ & GPS growth in tonnes/ha in region $(s)$ \\
\hline$N c_{s}$ & maize costs in $€ /$ tonne in region $(s)$ \\
\hline$G c_{s}$ & GPS costs in $€ /$ tonne in region $(s)$ \\
\hline Gass $, h, g^{2}$ & power revenue from manure of animal class $(h)$ with manure class $(g)$ in spatial unit $(s)$ \\
\hline & maximal share of poultry manure in biogas plant \\
\hline elc $p$ & price for one $\mathrm{kWh}$ electrical power \\
\hline load_h & full load hours (assumed to be 8000 hours per year) \\
\hline c fac & energy yield of energy crops in kWh electrical power per hectare (assumption: $364 \mathrm{kWh} /$ tonne $\mathrm{FM}$ ) \\
\hline
\end{tabular}


Biberacher and Warnecke, Spatially discrete linear optimization of manure transports...

Table 2. Basic model assumptions (a and b) and the interrelation of assumptions and results (c).

\begin{tabular}{|c|c|c|}
\hline $\begin{array}{l}\text { a) Each spatial unit can provide } \\
\text { nutrients (nitrogen, } \\
\text { phosphorous) from animal } \\
\text { husbandry: }\end{array}$ & $\begin{array}{l}\text { b) Each spatial unit } \\
\text { comprises areas of various } \\
\text { land uses: }\end{array}$ & $\begin{array}{l}\text { The extent to which the } \\
\text { manures are transported } \\
\text { depends on: }\end{array}$ \\
\hline $\begin{array}{l}\text { - The model has } 25 \text { 'farm animal } \\
\text { classes' with corresponding } \\
\text { animal farm manures ('manures'). } \\
\text { - Manures form a stock of local } \\
\text { nutrients and can be used to cover } \\
\text { some or all of the local crop } \\
\text { nutrient demand. The term local } \\
\text { refers to the crop class or farm } \\
\text { animal class and its manure in an } \\
\text { individual municipality. }\end{array}$ & $\begin{array}{l}\text { - Land use is described as 'crop } \\
\text { classes', containing both } \\
\text { permanent grassland ( } 2 \\
\text { classes) and crops grown on } \\
\text { arable land (11 classes). } \\
\text { - 'Crop classes' are given as } \\
\text { area per municipality. } \\
\text { - Each 'crop class' has a } \\
\text { specific nutrient demand } \\
\text { (nitrogen and phosphorous) } \\
\text { that is different in individual } \\
\text { soil-climate-areas. }\end{array}$ & $\begin{array}{l}\text { - Local manure production as } \\
\text { depending on nutrient excretion } \\
\text { rates etc., } \\
\text { - Local agricultural acreage } \\
\text { available for manure application, } \\
\text { - Technical measures to decrease } \\
\text { transport effort, } \\
\text { - Scenario constraints regarding } \\
\text { manure nutrients application as } \\
\text { depending on a range of } \\
\text { parameters, and } \\
\text { - Manure availability after } \\
\text { transportation between } \\
\text { municipalities as depending on } \\
\text { scenario constraints. }\end{array}$ \\
\hline
\end{tabular}

\subsection{Model equations}

The model is implemented as linear optimization model. The relations and equations in the model use the notations shown in Table 1. Relation (1) describes the combination and amount of manure applied to each of the crop classes in each of the spatial units. Relation (2) describes the combination and amount of excreta dropped directly on the pastures classes. The excreta dropped on pastures cannot be subject to relocation. Relations (1) and (2) prevent exceeding the constraints for manure nutrient application and nutrient excretion on pastures. The fertilizer demand of the crop classes can but must not be covered by animal manure nutrients. The constraints can be defined and altered for individual scenarios.

$$
\begin{array}{ll}
\sum_{h, g}\left(d_{s, c, h, g} \cdot b_{h, g, n}\right) \leq I_{n, c} \cdot a_{s, c} & \text { for all } s, n, c \\
\sum_{h}\left(u_{s, h, g} \cdot m_{h, g}-e x_{s, h, g}\right) \leq I_{n, f} \cdot a_{s, f} & \text { for all } s, n, f \text { and } g \text { in manure class "pasture excreta" }
\end{array}
$$

For each spatial unit in the model region, equation (3) equates locally available manures and manures imported from other spatial units with local manure application, manures exported to other spatial units and manure transports beyond the model region $(e x)$. The latter is only accounted for if total regional manure production exceeds total regional manure application capacity which is determined by the model constraints.

$$
\sum_{r}\left(t_{r, s, h, g}\right)+u_{s, h, g} \cdot m_{h, g}=\sum_{c}\left(d_{s, c, h, g}\right)+\sum_{r}\left(t_{s, r, h, g}\right)+e x_{s, h, g} \quad \text { for all } s, h, g
$$

Biogas is integrated into the model as follows. The electrical power which is installed per spatial unit in the form of biogas plants is used as the capacity of the spatial unit to produce electricity from manure, maize and GPS via biogas production. The biogas capacity is required to be at least as large as the input of manure, maize and GPS as a whole (expressed in electrical power, relation (4)).

$$
\sum_{h, g}\left(b g_{s, h, g} \cdot G a s_{s, h, g}\right)+\left(f_{-} n_{s}+f_{-} g_{s}\right) \cdot c_{-} f a c \leq B_{s} \cdot l o a d_{-} h \quad \text { for all } s
$$

The input of maize into the biogas capacity must be a certain share of the total input or larger than that (expressed in electrical power), e.g. $70 \%(=0.43$, relation (5)).

$$
\sum_{h, g} b g_{s, h, g} \leq f_{-} n_{s} \cdot 0.43
$$

for all $s$

The maximum share of poultry manure which can be used in the biogas capacity per spatial unit is required to be smaller than or equal to a certain threshold (relation (6)). 
Biberacher and Warnecke, Spatially discrete linear optimization of manure transports...

$$
\sum_{p(h), g} b g_{s, p(h), g} \cdot \operatorname{Gas}_{s, p(h), g} \leq B_{s} \cdot \operatorname{load}_{-} h \cdot m p \quad \text { for all } s
$$

The overall sum of maize or GPS that is imported, exported and produced in each spatial unit is required to be used in the unit's biogas capacity (relations (7) and (8)).

$$
\begin{array}{lr}
\sum_{r}\left(t_{-} n_{r, s} \cdot t_{-} n_{s, r}\right)+o_{-} n_{s}=f_{-} n_{s} & \text { for all } s \\
\sum_{r}\left(t_{-} g_{r, s}-t_{-} g_{s, r}\right)+o_{-} g_{s}=f_{-} g_{s} & \text { for all } s
\end{array}
$$

The area that is used for the production of maize for biogas production may not be larger than the area that is used for growing maize for whatever usage (relation (9)).

$$
o_{-} n_{s} \cdot N g_{s}+o_{-} g_{s} \cdot G g_{s} \leq a_{s, \text { 'maiz' }^{\prime}} \text { for all } s
$$

Objective function (10) comprises all relevant costs and revenues. This includes the revenues from electricity production in biogas power plants, the costs for mineral fertilizers which are in competition to animal manure in covering fertilizer demand and transport costs $(k)$ for animal manure among the whole model region. Global transport costs $(p)$ facilitate the export $(e x)$ of manure from the model region if the costs for manure relocation between the spatial units are higher than the costs for mineral fertilizer.

$$
\begin{aligned}
& \operatorname{Min} \sum_{s, r, h, g}\left(t_{s, r, h, g} \cdot w_{s, r} \cdot k\right)+\sum_{s, h, g}\left(e x_{s, h, g} \cdot p\right)+\sum_{s, n, c}\left(I_{n, c} \cdot a_{s, c}-\sum_{h, g}\left(d_{s, c, h, g} \cdot b_{h, g, n}\right)\right) \cdot z_{n} \\
& -\left(\sum_{s, h, g}\left(b g_{s, h, g} \cdot G a s_{s, h, g}\right)-\sum_{s}\left(f_{-} n_{s}+f g_{s}\right) \cdot c_{-} f a c\right) \cdot e l c_{-} p \\
& +\sum_{s}\left(o_{-} n_{s} \cdot N c_{s}+o_{-} g_{s} \cdot G c_{s}\right)
\end{aligned}
$$

\section{RESULTS}

Based on the given constraints regarding nutrient balance on farmland, livestock and biogas power plant capacity, the model comes out with an optimal transport logistic for animal manure and energy crops between neighbouring spatial units (Figure 1). Liquid manure largely remained in the spatial unit where it originated from while solid manure was transported over larger distances. The major transport direction was from the high intensity animal farming region in the west (with a surplus in animal manure nutrients) to the arable farming region in the east of the region (Figure 1 above). Transport of energy crops between municipalities occurred in some clusters of municipalities with higher biogas production (especially in the west), while other clusters of municipalities with higher biogas production were rather self-sufficient (e.g. in the middle north; Figure 1 below). An overall of $74 \%$ of the biogas produced in the region was generated from maize silage, $26 \%$ was generated from manure. Solid manure served as main manure input into the biogas plants. Table 3 aggregates the results for the entire state of Lower Saxony. Only $25 \%$ of the nitrogen demand of the crops in the region was covered by manure. For the remaining $75 \%$, artificial fertilizers proved cheaper at the given prices than transporting manure over larger distances.

Table 3. Results for the entire region of Lower Saxony.

\begin{tabular}{|l|l|l|}
\hline Animal manure transported [km*tonnes] & $2.532 \mathrm{e}+11$ & $\begin{array}{l}41 \% \text { liquid manure, } \\
59 \% \text { solid manure }\end{array}$ \\
\hline Energy crops transported [km*tonnes] & $1.772 \mathrm{e}+10$ & \\
\hline Energy crops produced [M tonnes] & 8.9 & \\
\hline $\begin{array}{l}\text { Animal manure used as fertilizer on farmland } \\
{[\mathrm{M} \text { tonnes] }}\end{array}$ & $\begin{array}{l}21 \text { (including } 103 \mathrm{k} \text { tonnes } \mathrm{N}, \\
48 \mathrm{k} \text { tonnes } \mathrm{P}, 125 \mathrm{k} \text { tonnes } \mathrm{K})\end{array}$ & $\begin{array}{l}98 \% \text { liquid manure, } \\
2 \% \text { solid manure }\end{array}$ \\
\hline Artificial fertilizer used on farmland [k tonnes] & $\mathrm{N}: 308, \mathrm{P}: 174, \mathrm{~K}: 307$ & \\
\hline Surplus of animal manure [M tonnes] & 11 (including $58 \mathrm{k}$ tonnes $\mathrm{N}$, & $\begin{array}{l}99 \% \text { liquid manure, } \\
1 \% \text { solid manure }\end{array}$ \\
\hline & $31 \mathrm{k}$ tonnes $\mathrm{P}, 60 \mathrm{k}$ tonnes $\mathrm{K})$ & $1 \%$ liquid manure, \\
Power produced as biogas $[\mathrm{GWh}]$ & 4,375 & $\begin{array}{l}25 \% \text { solid manure, } \\
74 \% \text { maize silage }\end{array}$ \\
\hline
\end{tabular}



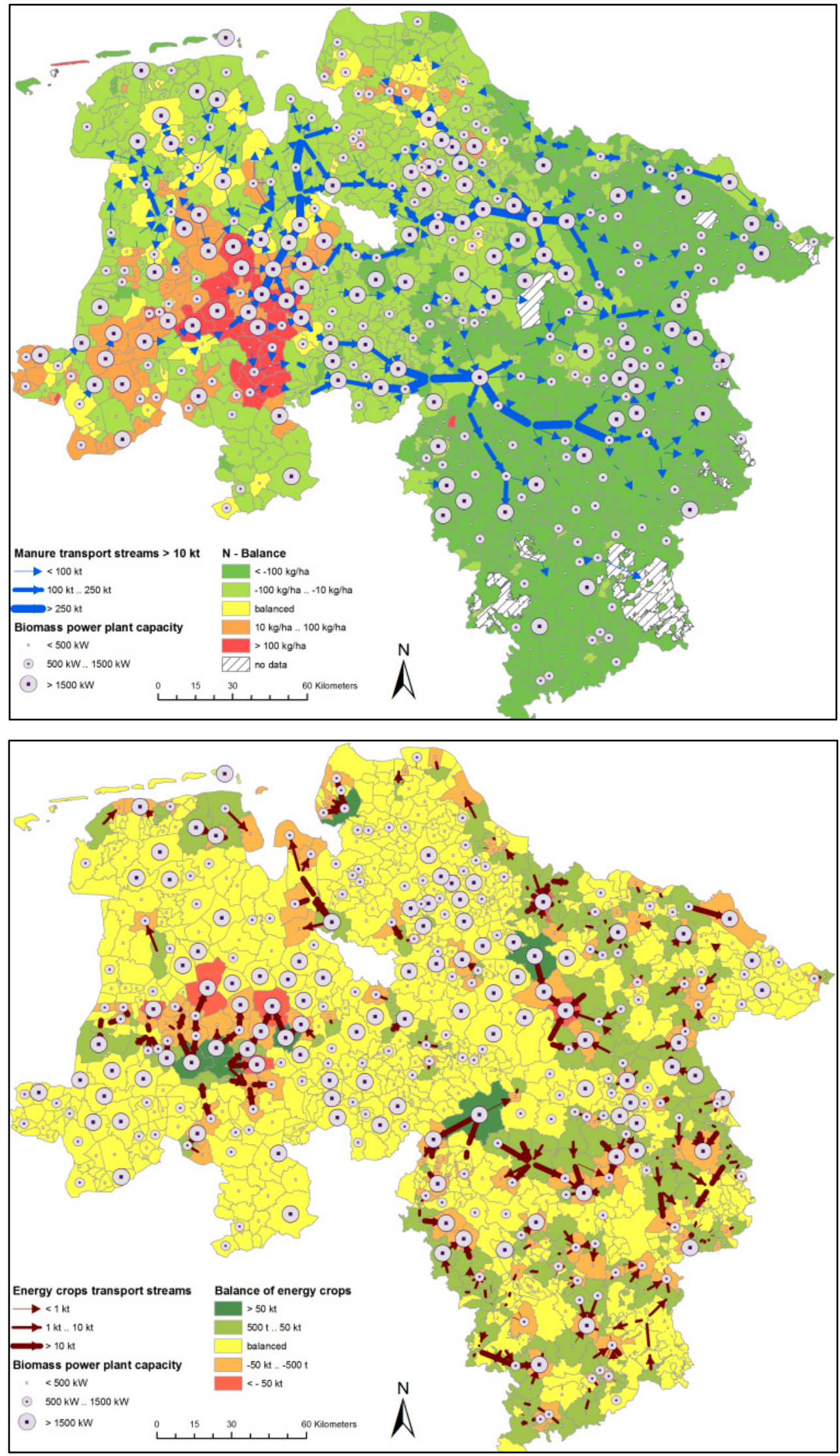

Figure 1. $\mathrm{N}$ balance with related manure transport flows (above) and energy crop balance with related transport flows (below), both merged with the biogas plant capacity and both on basis of the individual spatial units. 
Biberacher and Warnecke, Spatially discrete linear optimization of manure transports...

\section{DISCUSSION AND CONCLUSIONS}

In a complex system environment with a geographical distribution of numerous animal classes, crop classes and biogas plant capacities, overall system logistics are challenging. In a multidimensional approach, the model presented treats the most relevant aspects which must be considered in high intensity animal farming and in using manure as fertilizer and for biogas production. All material flows which occur to balance nutrient demands in agriculture and energy crop demands for biogas plants are part of this system process optimization. The model treats the relevant drivers endogenously and comes out with an optimal result.

Whenever costs for nutrients are used as model input, transport costs of the otherwise cost-free animal excreta are contrasted with the costs for artificial fertilizers. In this competition, animal manure that is economically in excess is not used as fertilizer. This surplus manure is not considered further in the model. In the scenario chosen, $11 \mathrm{M}$ tons of animal manure are in excess from the economic point of view of the scenario. Almost all of the excess comes in the form of slurry because the model optimized the use of the available solid and liquid manures: Liquid manures mostly consists of water, hence they have a smaller fertilizer value and a smaller biogas production value than solid manures.

With the nutrient constraints, a pretty realistic scenario was built. It results in a legally imposed manurenutrient excess per hectare agricultural land that is, while quite large in Lower Saxony's west, lower than it would be if nutrient best management practices were built into a scenario (Warnecke et al. 2010). But even at the legal limits and the rather high costs for artificial fertilizers assumed in this study's scenario, a large share of the animal manure nutrients cannot be used economically feasible. In reality, the legal limits have to be respected, hence all manure that is nutrient-wise and legally in excess has to be transported to regions with lower animal densities, no matter if economically sensible or not.

Most of the power produced in the scenario comes from maize. This is a result of (a) the constraint that at least $60 \%$ (mass \%) of the input into the power plant must be maize and (b) that animal manure has a lower energy density than maize. This is be particularly true for liquid manures which make up only $1 \%$ of the energy generated in the biogas plants of the scenario as opposed to the $25 \%$ coming from solid manures.

In the current version of the model, biogas digestates are not yet integrated into the nutrient balance nor into the transports. This is a prerequisite to enable more realistic analyses in the future when the new German Fertilizer Ordinance will come into effect: It will include $\mathrm{N}$ from the plant material in the digestates in the threshold of using no more than $170 \mathrm{~kg} \mathrm{~N}$ per hectare from organic sources.

In general, the model framework enables for sensitivity studies on various impacts which trigger a system. In future studies, we expect to analyze aspects of co-existence of animal farming, arable farming and biogas production, e.g. with respect to environmental performance or revenue of a region. Other interesting fields to use the model are the distribution of rather scarce byproducts (incl. animal manure) in organic farming or the challenges associated with food input and human excreta output of large cities, especially under the premises of $\mathrm{P}$ constraints. Results from such studies may enable intelligent system setups and optimal logistics.

\section{REFERENCES}

Biberacher, M., Warnecke, S., Brauckmann, H.-J., and G. Broll (2009). A linear optimisation model for animal farm manure transports in regions with high intensity animal farming. In: Anderssen, R.S., Braddock, R.D., and L.T.H. Newham (eds) 18th World IMACS Congress and MODSIM09 International Congress on Modelling and Simulation, July 2009. Modelling and Simulation Society of Australia and New Zealand and International Association for Mathematics and Computers in Simulation, 470-476.

GAMS, General Algebraic Modelling System (2015), http://www.gams.com/ (accessed 21.06.2015)

German Fertilizer Ordinance (Düngeverordnung) (2007). Verordnung über die Anwendung von Düngemitteln, Bodenhilfsstoffen, Kultursubstraten und Pflanzenhilfsmitteln nach den Grundsätzen der guten fachlichen Praxis. Ausfertigungsdatum 10. Januar 2006 (BGBl. I S. 33). Düngeverordnung in der Fassung der Bekanntmachung vom 27. Februar 2007 (BGB1. I S. 221)

KTBL, Kuratorium für Technik und Bauwesen in der Landwirtschaft e.V. (2009). Faustzahlen Biogas. Darmstadt.

TSK, Niedersächsische Tierseuchenkasse (2009). Unpublished data on number of animals in the districts of Lower Saxony in December 2009.

Warnecke, S., Biberacher, M., Brauckmann, H.-J., and G. Broll (2010). Nutrient best management practices need regional material flow management for soil protection. In: Gilkes, R.J. and N. Prakongkep (eds) Proceedings of the 19th World Congress of Soil Science "Soil Solutions for a Changing World", August 2010. International Union of Soil Sciences, 168-171. 